\title{
Varenicline for smoking cessation: a narrative review of efficacy, adverse effects, use in at-risk populations, and adherence
}

This article was published in the following Dove Press journal:

Patient Preference and Adherence

I April 2016

Number of times this article has been viewed

\author{
Michael V Burke \\ J Taylor Hays \\ Jon O Ebbert
}

Mayo Clinic, Rochester, MN, USA
Correspondence: Jon O Ebbert

Mayo Clinic, 200 First Street SW,

Rochester, MN 55905, USA

$\mathrm{Tel}+\mathrm{I} 5852661944$

Fax + I 5852667900

Email ebbert.jon@mayo.edu

\begin{abstract}
Treating tobacco dependence is the most effective way to reduce tobacco-related death and disability. Counseling and pharmacotherapy have been shown to increase tobacco abstinence rates among smokers. Varenicline is the most effective monotherapy treatment for tobacco dependence; however, it is prescribed less often than indicated, and adherence is less than optimal. We conducted a literature review of the development, efficacy, safety, contraindications, and adverse effects of varenicline; including reviewing data regarding combination therapy, extended duration, and patient adherence. Varenicline was developed to work specifically on the factors that underlie nicotine addiction. Phase II and Phase III trials established dosing, safety profiles, and efficacy. Postmarketing research raised concerns about neuropsychiatric and cardiac effects, resulting in warning labels being added and modified to encourage discussions with patients weighing the risks and benefits. While more research is needed, evidence is strong that varenicline is safe and effective in treating tobacco dependence among people who are at higher risk for neuropsychiatric symptoms and cardiovascular disease. The effectiveness of varenicline can be improved by taking it in combination with other medications, enhancing patient adherence and extending the duration of treatment.
\end{abstract}

Keywords: tobacco use, tobacco use cessation, treatment, medication adherence, drug therapy, safety

\section{Introduction}

Smoking causes nearly one in every five deaths in the US. ${ }^{1}$ Globally, annual tobaccorelated deaths will increase from 6 million in 2010 to 10 million by $2040 .^{2}$ Individuals who stop smoking live longer with fewer tobacco-related diseases. Elderly people can prevent more adverse cardiovascular outcomes by stopping smoking than with any other preventive treatment including aspirin, statins, exercise, or diet. ${ }^{3}$ Smoking cessation improves health outcomes for surgical patients and patients with diabetes or psychiatric comorbidities. ${ }^{4-8}$

Tobacco dependence treatments are effective in helping people stop smoking. ${ }^{9}$ The most effective interventions consist of both medication and counseling. ${ }^{10,11}$ The US Food and Drug Administration (FDA) has approved seven medications for helping people stop smoking: five nicotine replacement medications (patch, gum, lozenge, inhaler, and nasal spray), varenicline, and bupropion. ${ }^{9}$ Nicotine replacement medications are all equally efficacious for improving smoking abstinence rates in comparison with each other and have comparable efficacy compared with bupropion. Nicotine replacement therapy (NRT) used in combination (eg, patch + gum or patch + nasal spray) improve abstinence outcomes compared with single NRT. ${ }^{12,13}$ 
Varenicline is a nonnicotine medication designed specifically for the treatment of tobacco use disorder, and the most efficacious single agent for abstinence outcomes. However, varenicline is underutilized, in part because prescribers may weigh the potential adverse effects as more salient than the potential benefits from varenicline for treating tobacco use disorder. ${ }^{14,15}$

In this article, we will discuss our review of the literature by describing the development, mechanism of action, and key clinical trials used for regulatory approval of varenicline. We reviewed postmarketing concerns about adverse effects from varenicline, particularly the increased risk for neuropsychiatric and cardiovascular symptoms and current research on the use of varenicline with patients at risk for psychiatric adverse effects and cardiovascular events. Finally we reviewed studies evaluating outcomes from combining varenicline with another tobacco treatment medication, and studies evaluating the impact of adherence on abstinence.

\section{Methods}

We conducted a literature review using "varenicline" as the primary search term and "development", "clinical trial", "adverse events", "contraindications", "cardiovascular symptoms", "mental health", "neuropsychiatric symptoms", "combination therapy", and "adherence" as companion terms. We reviewed PubMed abstracts from January 1966 through December 2015 and selected unique clinical trials and review studies relevant to the objectives of this review and summarized the studies in narrative.

\section{Results}

\section{Varenicline mechanism of action}

Nicotine is primarily responsible for the reinforcement, tolerance, withdrawal symptoms, and compulsive use that characterizes tobacco use disorder; however, it is not the direct cause of the health problems attributable to tobacco use, as demonstrated in both animal and human studies. Inhaled cigarette smoke delivers nicotine rapidly to the brain where it binds to nicotinic acetylcholine receptors (nAChR), releasing various neurotransmitters. Twelve types of subunits of $\mathrm{nAChR}$ have been identified in the mammalian brain, with the effect of nicotine occupying specific receptors dependent upon a number of factors including location, type, and function of the neuronal circuit. ${ }^{16,17}$ Nicotine binding to nAChR $\alpha 4 \beta 2$ receptor sites in the mesolimbic and mesocortical pathway, activates circuits that produce dopamine, a neurotransmitter that regulates conditioned learning and rewardmotivated behavior. ${ }^{17,18}$ Upregulation of these receptors, adaptation, and sensitization lead to the compulsive use of nicotine to maintain homeostasis, all of which make the $\alpha 4 \beta 2$ receptor an effective pharmacologic target. ${ }^{17,19}$

The development of varenicline was, in part, based upon the structure and function of cytisine, a naturally occurring insecticide. ${ }^{20,21}$ Cytisine is found in a number of different plants, with high amounts found in the leaves and seeds of Cytisus laburnum (golden rain tree). In place of tobacco, soldiers smoked leaves of this tree during World War II. Cytisine has subsequently been marketed for 40 years in Eastern Europe for smoking cessation under the trade name Tabex $^{\circledR}$, but is not currently approved for use outside of Eastern Europe. A review and meta-analysis of seven controlled trials concluded that cytisine has smoking cessation efficacy comparable to other drugs currently available in the US. ${ }^{22}$ Another review described the medication as promising and the efficacy for the treatment of tobacco dependence as modest. ${ }^{23}$

Both varenicline and cytisine target the $\alpha 4 \beta 2$ receptor. ${ }^{20,21}$ In vitro and in vivo animal studies found that cytisine has a lower affinity for the $\alpha 4 \beta 2$ compared to its affinity to other nAChR receptors. ${ }^{24}$ Varenicline was developed to improve binding to the $\alpha 4 \beta 2$ receptor to enhance efficacy for smoking cessation. ${ }^{21}$ Animal studies demonstrate that varenicline has a greater affinity for the $\alpha 4 \beta 2$ receptor than cytisine, and that it stimulates dopamine release. ${ }^{21}$ Binding of the partial agonist varenicline to the $\alpha 4 \beta 2$ receptor results in a dopamine release that is half of that released by the pure agonist nicotine. Varenicline reduces nicotine seeking and intake in nicotineaddicted rats; however, it does not cause upregulation and sensitization of $\mathrm{nAChR}$, providing a rationale for its use as a smoking cessation treatment. ${ }^{25-27}$ Because of its relatively long half-life, compared with nicotine, varenicline also acts as an antagonist, blocking the occupied receptors from additional stimulation from nicotine. ${ }^{27,28}$ Varenicline is minimally metabolized, with $>90 \%$ being excreted unchanged in the urine in both animals and humans. Varenicline has no known clinically important drug-drug interactions. ${ }^{29}$

\section{Dosing studies}

To determine dosing and tolerability of varenicline in humans, a clinical trial was conducted randomizing nonsmoking subjects to receive escalating doses of either varenicline or placebo. ${ }^{28}$ Doses were administered in the morning and evening under fasting and nonfasting conditions. A maximum daily dose of up to $3.0 \mathrm{mg}$ for smokers and $1.0 \mathrm{mg}$ for nonsmokers was found to be the recommended upper limits due to frequent nausea and vomiting at 
higher doses. The pharmacokinetics were not affected by food, time of dosing, or smoking status.

Another study to determine optimal dosing was designed as a double-blind study with a self-regulated flexible dosing schedule. ${ }^{30}$ Smokers motivated to quit $(\mathrm{N}=320)$ were randomized to receive either varenicline or placebo for 12 weeks. After both groups were titrated to the typical target dose of $2.0 \mathrm{mg}$ per day during week 1 , they were instructed to use between 0.5 and $2.0 \mathrm{mg}$ per day for weeks $2-12$, using the dose that they believed best balanced adverse effects and therapeutic effects. Superior 4-week continuous abstinence rates were observed in the varenicline treated group at weeks 7, 12, 24, and 52. Adherence in both groups was high, although the varenicline group tapered dosage over time compared with placebo. The varenicline group used an average daily dose of $1.3 \mathrm{mg}$ compared to $1.6 \mathrm{mg}$ in the placebo group. The self-titrated dosing was safe and efficacious for smoking cessation in comparison with placebo, and resulted in less nausea than typically seen in other clinical trials of varenicline.

\section{Phase II studies}

To further establish the safety, dosing, and efficacy of varenicline, two multicenter, randomized, double-blind, placebo-controlled Phase II clinical trials were conducted in cigarette smokers. ${ }^{31,32}$

One study enrolled 638 cigarette smokers randomly assigned to varenicline $(0.3 \mathrm{mg}$ daily, $1.0 \mathrm{mg}$ daily, $1.0 \mathrm{mg}$ twice daily), bupropion-SR (150 mg twice daily), or placebo for 7 weeks. ${ }^{31}$ Short-term smoking abstinence rates were defined as the proportion of subjects achieving continuous 28-day smoking abstinence any time in the treatment period. A dose-response relationship for varenicline was observed for continuous abstinence rates for $1.0 \mathrm{mg}$ once daily $(37.3 \%$, $P<0.001)$ and $1.0 \mathrm{mg}$ twice daily $(48 \%, P<0.001)$ significantly greater than placebo (17.1\%). Varenicline consistently reduced craving scores and measures of smoking satisfaction and enjoyment throughout 6 weeks of treatment.

The second study randomized 647 smokers to varenicline ( $0.5 \mathrm{mg}$ twice daily, $1.0 \mathrm{mg}$ twice daily) or to placebo for 12 weeks. ${ }^{32}$ Subgroups received either the full dose initially or titrated to the full dose over 1 week. Varenicline significantly increased continuous abstinence compared with the placebo, week 4 to week 7, and in the 9- to 12-week period. Nonsignificant differences were observed between the different dosing and titration subgroups. Varenicline significantly reduced the urge to smoke in all groups and reduced the reinforcing effects of cigarette smoke among those continuing to smoke. Titration resulted in less nausea compared with the nontitrated groups.

Both studies reported higher rates of nausea, abnormal dreams, taste perversion, flatulence, constipation, and headache with varenicline compared with the placebo group. No differences were observed in discontinuation rates due to adverse events. The 12-week study found that nausea was dose-dependent, but less so in the subgroup that was titrated to the target dose.

\section{Phase III studies}

The FDA approved varenicline for use beginning in 2006, after three large Phase III trials determined the drug to be safe and efficacious. Two of the three trials were identical in design and compared varenicline with bupropion and placebo, each for 12 weeks with a 40 -week nontreatment follow-up. ${ }^{33,34}$ The third trial was designed to test the effect on relapse rate by extending use of varenicline from 12 to 24 weeks. $^{35}$

The two trials comparing varenicline, bupropion, and placebo were randomized, double-blind, multicenter trials. The primary outcome was 4 weeks continuous abstinence at 12 weeks. Both studies had similarly significant results with $44 \%$ abstinence in the varenicline group compared with $30 \%$ in the bupropion group, and $18 \%$ in the placebo group. At 1 year, $22 \%-23 \%$ of smokers remained abstinent in the varenicline group compared to $15 \%-16 \%$ in the bupropion group, and $8 \%-10 \%$ in the placebo group. Interestingly, both studies demonstrated a steadily increasing 7-day point prevalence smoking abstinence rate from quit day through week 8 , suggesting a cumulative effect over time on smoking abstinence with varenicline.

The third Phase III trial recruited and treated 1,927 smokers for 12 weeks with open-label varenicline, $1.0 \mathrm{mg}$ twice per day. ${ }^{35}$ Sixty-three percent $(n=1,210)$ of smokers who were abstinent at 12 weeks were randomized to a doubleblind study period with an additional 12 weeks varenicline or placebo. Smoking abstinence from weeks 12 to 24 were significantly higher in the varenicline group compared to placebo (70\% vs 49.6\%; odds ratio [OR] 2.48; $P<0.001$ ); this difference persisted at 1 year $(43.6 \%$ vs $36.9 \%$; OR $1.34 ; P=0.02)$.

\section{Phase III trial adverse events}

Three large randomized control trials demonstrated that varenicline is safe at the $1.0 \mathrm{mg}$ dosage twice per day. The most common adverse event was nausea reported by $29 \%-30 \%$ of participants. Nausea was usually described as 
mild or moderate; the rate of treatment discontinuation due to nausea was only $2.5 \%$. The other common adverse events were headache, insomnia, and vivid dreams. In the relapse prevention trial during weeks 13-24, adverse events were similar between the varenicline and placebo groups. ${ }^{35}$ Only $1.2 \%$ of patients reported nausea as an adverse event during the additional 12 weeks.

\section{Conclusions from Phase II and Phase III studies}

Studies confirmed that varenicline is more efficacious than bupropion for smoking cessation. Extending the use of varenicline from 12 to 24 weeks reduces relapse and improves smoking cessation outcomes. The overall safety and tolerability of varenicline in these studies is excellent. The FDA approved the use of varenicline in 2006 based upon the results of these Phase II and Phase III trials.

\section{Adverse events and FDA warnings}

In 2009, the FDA mandated a boxed label warning for both varenicline and bupropion about possible serious neuropsychiatric side effects based upon postmarketing surveillance. The warning stated that reports of changes in behavior (hostility, agitation, depressed mood, and suicidal thoughts or actions) had been associated with use of varenicline and bupropion.

A pooled analysis including ten completed randomized clinical trials was conducted to evaluate associations between varenicline and neuropsychiatric events. ${ }^{36}$ The studies included 3,091 participants receiving at least one dose of varenicline and 2,005 participants who received placebo for 6,12 , or 52 weeks. No difference in psychiatric disorders was reported between the two groups. The varenicline group reported more sleep disturbances.

The FDA sponsored two retrospective cohort studies to explore the relationship between varenicline and neuropsychiatric events. ${ }^{37,38}$ One study by the Department of Veterans' Affairs examined the number of psychiatric hospitalizations in 14,131 varenicline users versus an equal number using NRT 30 days after the medication was prescribed. The investigation yielded no statistical difference between the groups. A second study conducted by the Department of Defense matched 10,814 varenicline users with NRT users and also observed no difference in psychiatric hospitalizations between the groups. The FDA reviewed this evidence in 2011 and determined that it was insufficient to remove the labeled warning as the above studies limited adverse events to hospitalizations only. ${ }^{37}$
To further explore this issue, Gibbons and Mann ${ }^{39}$ re-analyzed data from 17 studies conducted by Pfizer that included 8,027 participants who used varenicline. Of these, 1,004 participants had preexisting psychiatric disorders. The analysis found that varenicline significantly increased nausea but not depression, agitation, or suicidal thoughts or events. A recent meta-analysis of 39 randomized control trials, comprising 10,761 participants, observed no increased risk of suicide, suicide attempt or ideation, depression, or death in the 5,817 treated with varenicline, compared with the 4,944 participants taking the placebo. ${ }^{40}$ The FDA is continuing to evaluate ongoing reports of adverse effects, but is waiting for the results of a large safety trial specifically designed to evaluate neuropsychiatric events as outcomes. ${ }^{37}$

In 2012, the FDA issued an updated Drug Safety Communication warning for cardiovascular risk in smokers treated with varenicline. ${ }^{41}$ A meta-analysis of 14 trials did find an increased risk of serious cardiovascular events associated with varenicline use. ${ }^{42}$ However, this study was limited by the small number of events in both the varenicline- and placebo-treated groups, as well as the fact that many of the events occurred after the varenicline had been discontinued. ${ }^{43}$ A subsequent review and meta-analysis of 22 trials found no increase in cardiovascular events among varenicline users when including events that occurred during or within 30 days of varenicline administration. ${ }^{44}$ A network meta-analysis, including 18 randomized clinical trials of varenicline, showed no increased cardiovascular risk with the use of varenicline. ${ }^{45}$

\section{Varenicline in patients with psychiatric conditions}

A study of outpatients with stable schizophrenia was conducted to prospectively assess psychiatric symptoms, adverse events, and smoking outcomes during treatment with varenicline. ${ }^{46}$ One hundred and twelve outpatients who smoked $>10$ cigarettes per day were provided cognitive behavioral counseling and open label varenicline $0.5 \mathrm{mg} /$ day for 3 days, $0.5 \mathrm{mg}$ twice per day for 3 days and then $1.0 \mathrm{mg}$ twice per day for 11 weeks. Psychiatric symptoms were assessed for the 1 month period prior to the target quit date (week 4) and 2 months after. From baseline to week 12, psychiatric symptoms improved, including ratings of psychotic symptoms, depression, and nicotine withdrawal. At week 12, the 14 -day continuous abstinence was $47.3 \%$.

Because relapse to smoking is common in smokers with serious mental illness, a study was conducted to determine if extended use of varenicline would prolong abstinence in 
smokers diagnosed with schizophrenia and bipolar disease. ${ }^{47}$ At the end of 12 weeks of open label varenicline among study participants with schizophrenia or bipolar disorder, 87 participants who had abstained from smoking were randomized to receive counseling and varenicline $(1.0 \mathrm{mg}$ twice per day) or counseling and placebo for an additional 40 weeks. At the end of the 52-week treatment phase, $60 \%$ were abstinent in the varenicline group compared with $19 \%$ in the placebo group (OR, 6.2; 95\% confidence interval [CI], 2.2-19.2; $P<0.001)$. No differences were observed in psychiatric symptom ratings or psychiatric adverse events between the two groups.

\section{Combination therapy with varenicline}

A number of studies have observed that combining varenicline with other smoking cessation medications can increase abstinence rates compared with varenicline alone. Koegelenberg et $\mathrm{al}^{48}$ observed that combination therapy with the nicotine patch and varenicline improved smoking abstinence rates when compared with varenicline alone. In this study, 435 smokers who smoked $>20$ cigarettes per day were randomized to varenicline and a $15 \mathrm{mg}$ nicotine patch or varenicline and a placebo patch. The nicotine patch was started 2 weeks prior to the quit date and varenicline 1 week prior; the medication was continued for another 12 weeks. The combination therapy group had higher 4-week continuous abstinence smoking rates at the end of treatment $(55.4 \%$ vs $40.9 \%$; OR $1.85 ; 95 \%$ CI $1.19-2.89 ; P=0.007)$ and at 24 weeks (49.0\% vs 32.6\%; OR 1.98; 95\% CI 1.25-3.14; $P=0.002)$, than the monotherapy group.

In another study of combination therapy with varenicline and the $21 \mathrm{mg}$ nicotine patch, combination therapy did not increase smoking abstinence rates compared to varenicline alone. ${ }^{49}$ In this randomized study of 341 smokers, participants started the nicotine patch at a quit date 1 week after the participants began a varenicline titration. No significant differences were observed between the groups in prolonged abstinence or 7-day point prevalence abstinence at weeks 8 , 12 , and 24 . A subgroup analysis of this study observed that participants smoking $>29$ cigarettes per day were more likely to be abstinent from smoking at 12 weeks (OR 1.39; 95\% CI 1.2-2.5) and 24 weeks (OR 1.46; 95\% CI 1.2-2.8) if they received combination therapy.

The efficacy of combination therapy with varenicline and bupropion for smoking cessation has been evaluated. In another study, 506 smokers were randomized to 12 weeks of treatment with varenicline + bupropion versus varenicline alone. ${ }^{50}$ The primary outcome was carbon monoxide-confirmed 7-day point prevalence abstinence at weeks 12, 26, and 52; differences between the two groups were not significant. A subgroup analysis observed that participants who smoked $>20$ cigarettes per day (or had higher nicotine dependence) and received combination therapy had significantly higher rates of prolonged smoking abstinence outcomes at 3, 6, and 12 months.

\section{Varenicline for smoking reduction}

Most smokers want to quit, but many are not ready to set a quit date at the time they are seen in the clinic. Varenicline may be effective in helping those smokers to reduce their tobacco use and eventually stop smoking. In a study enrolling smokers who had no intention to quit in the next 30 days but were willing to reduce their smoking, 1,510 smokers were randomized to varenicline or placebo. ${ }^{51}$ Medications were continued to week 24 and subjects were followed to week 52. Participants were instructed to reduce smoking by $50 \%$ by week $4,75 \%$ by week 8 , and to attempt to quit by week 12 . From weeks 15-24, $32.1 \%$ of those in the varenicline group were biochemically confirmed to have been continuously abstinent, compared with $6.9 \%$ in the placebo group (risk difference, $25.2 \%$; $95 \% \mathrm{CI}$, 21.4-29.0; relative risk, 4.6; 95\% CI, 3.5-6.1). From weeks $21-52,27 \%$ of the varenicline group remained abstinent compared to $9 \%$ of the placebo group (risk difference, $17.1 \%$; $95 \%$ CI, 13.3-20.9; relative risk, 2.7; 95\% CI, 2.1-3.5).

\section{Adherence}

Better adherence to varenicline improves outcomes but adherence is often suboptimal. ${ }^{52}$ Suehs et $\mathrm{al}^{53}$ retrospectively evaluated pharmacy claims data to examine the relationship between out-of-pocket expenses and varenicline utilization. Adherence was calculated based upon medications dispensed as covered for up to 12 weeks after initial coverage. The mean treatment duration was 50.8 days. Greater varenicline outof-pocket expense was significantly associated with lower days of varenicline use and lower odds of receiving a refill. The authors concluded that among Medicare beneficiaries, newly beginning varenicline, adherence was suboptimal and lower adherence and lower odds of refilling were associated with higher out-of-pocket costs. ${ }^{53}$

Liberman et $\mathrm{al}^{54}$ retrospectively studied patients enrolled in a primary care setting - private health plan to examine adherence to varenicline. Of the 1,477 patients who had received a prescription for varenicline and had a subsequent follow-up within 12 months, 823 (55.7\%) never initiated varenicline. Of the 654 patients who initiated varenicline, $359(54.9 \%)$ completed a full 12-week course of therapy 
and $295(45.1 \%)$ were partially adherent. There were no significant differences in abstinence outcomes between the partially adherent and the nonadherent patients $(27.8 \%$ and $31.2 \%$, respectively). Outcomes among patients who were fully adherent were significantly better at $50.7 \% .{ }^{54}$

There are promising interventions to improve adherence to tobacco dependence treatments, although more research is needed. ${ }^{55}$ A small study of adherence to varenicline among African American smokers found that adherence could be improved with increased and targeted counseling support. ${ }^{56}$

\section{Conclusion}

Tobacco dependence is the leading cause of preventable death in the US. Counseling and medications can help many patients to achieve abstinence. Varenicline is the most effective single agent for treating tobacco use disorder, however, it continues to be prescribed less often than indicated.

Clinical trials have consistently demonstrated that varenicline is a safe and effective agent for smoking cessation. Evidence supports that varenicline can be used safely by a wide variety of patients and is not contraindicated for people with mental health problems or cardiovascular disease; although patients and providers should determine varenicline prescription only after a discussion about the potential risks and benefits.

The efficacy of varenicline can be improved by combining it with NRT and bupropion, especially for people who are more heavily dependent. Extended use of varenicline can improve abstinence outcomes. Adherence improves outcomes and discussions with patients can improve adherence.

\section{Disclosure}

Dr Burke has provided continuing medical education lectures supported by Pfizer, most recently in 2011. Dr Ebbert reports research grant support from Pfizer. Dr Hays reports research grant support from Pfizer. The authors report no other conflicts of interest in this work.

\section{References}

1. U.S. Department of Health and Human Services, Centers for Disease Control and Prevention, National Center for Chronic Disease Prevention and Health Promotion, Office on Smoking and Health. The Health Consequences of Smoking-50 Years of Progress: A Report of the Surgeon General. Atlanta, GA: U.S. Department of Health and Human Services, Centers for Disease Control and Prevention, National Center for Chronic Disease Prevention and Health Promotion, Office on Smoking and Health; 2014.

2. Jha P, Peto R. Global effects of smoking, of quitting, and of taxing tobacco. N Engl J Med. 2014;370(1):60-68.

3. Gohlke H. Is it worth offering cardiovascular disease prevention to the elderly? Eur J Prev Cardiol. 2013;20(1):121-126.
4. Cavazos-Rehg PA, Breslau N, Hatsukami D, et al. Smoking cessation is associated with lower rates of mood/anxiety and alcohol use disorders. Psychol Med. 2014;44(12):2523-2535.

5. Doll R, Peto R, Boreham J, Sutherland I. Mortality in relation to smoking: 50 years' observations on male British doctors. BMJ. 2004; 328(7455): 1519.

6. Kenfield SA, Stampfer MJ, Rosner BA, Colditz GA. Smoking and smoking cessation in relation to mortality in women. JAMA. 2008; 299(17):2037-2047.

7. Nagrebetsky A, Brettell R, Roberts N, Farmer A. Smoking cessation in adults with diabetes: a systematic review and meta-analysis of data from randomised controlled trials. BMJ Open. 2014;4(3):e004107.

8. Thomsen T, Villebro N, Moller AM. Interventions for preoperative smoking cessation. Cochrane Database Syst Rev. 2014;3:CD002294.

9. Fiore M. Treating Tobacco Use and Dependence: 2008 Update: Clinical Practice Guideline. Collingdale: DIANE Publishing; 2008.

10. Stead LF, Lancaster T. Behavioural interventions as adjuncts to pharmacotherapy for smoking cessation. Cochrane Database Syst Rev. 2012;12:CD009670.

11. Stead LF, Lancaster T. Combined pharmacotherapy and behavioural interventions for smoking cessation. Cochrane Database Syst Rev. 2012; 10:CD008286.

12. Cahill K, Stevens S, Perera R, Lancaster T. Pharmacological interventions for smoking cessation: an overview and network meta-analysis. Cochrane Database Syst Rev. 2013;5:CD009329.

13. Stead LF, Perera R, Bullen C, et al. Nicotine replacement therapy for smoking cessation. Cochrane Database Syst Rev. 2012;11:CD000146.

14. Kim Y, Kornfield R, Shi Y, et al. Effects of televised direct-to-consumer advertising for varenicline on prescription dispensing in the United States, 2006-2009. Nicotine Tob Res. Epub 2015 Sep 18.

15. Hays JT, Ebbert JO. Adverse effects and tolerability of medications for the treatment of tobacco use and dependence. Drugs. 2010;70(18): 2357-2372.

16. Arneric SP, Holladay M, Williams M. Neuronal nicotinic receptors: a perspective on two decades of drug discovery research. Biochem Pharmacol. 2007;74(8):1092-1101.

17. Subramaniyan M, Dani JA. Dopaminergic and cholinergic learning mechanisms in nicotine addiction. Ann N Y Acad Sci. 2015;1349:46-63.

18. Tapper AR, McKinney SL, Nashmi R, et al. Nicotine activation of alpha4* receptors: sufficient for reward, tolerance, and sensitization. Science. 2004;306(5698):1029-1032.

19. Benowitz NL. Nicotine addiction. $N$ Engl J Med. 2010;362(24): 2295-2303.

20. Etter JF. Cytisine for smoking cessation: a literature review and a metaanalysis. Arch Intern Med. 2006;166(15):1553-1559.

21. Coe JW, Vetelino MG, Bashore CG, et al. In pursuit of alpha4beta2 nicotinic receptor partial agonists for smoking cessation: carbon analogs of (-)-cytisine. Bioorg Med Chem Lett. 2005;15(12):2974-2979.

22. Hajek P, McRobbie H, Myers K. Efficacy of cytisine in helping smokers quit: systematic review and meta-analysis. Thorax. 2013;68(11): 1037-1042.

23. Cahill K, Stead LF, Lancaster T. Nicotine receptor partial agonists for smoking cessation. Cochrane Database Syst Rev. 2012;4:CD006103.

24. Mihalak KB, Carroll FI, Luetje CW. Varenicline is a partial agonist at alpha4beta2 and a full agonist at alpha7 neuronal nicotinic receptors. Mol Pharmacol. 2006;70(3):801-805.

25. Coe JW, Brooks PR, Vetelino MG, et al. Varenicline: an alpha4beta2 nicotinic receptor partial agonist for smoking cessation. J Med Chem. 2005;48(10):3474-3477.

26. Cohen C, Bergis OE, Galli F, et al. SSR591813, a novel selective and partial alpha4beta2 nicotinic receptor agonist with potential as an aid to smoking cessation. J Pharmacol Exp Ther. 2003;306(1):407-420.

27. Rollema H, Coe JW, Chambers LK, Hurst RS, Stahl SM, Williams KE. Rationale, pharmacology and clinical efficacy of partial agonists of alpha4beta2 $\mathrm{nACh}$ receptors for smoking cessation. Trends Pharmacol Sci. 2007;28(7):316-325. 
28. Faessel HM, Smith BJ, Gibbs MA, Gobey JS, Clark DJ, Burstein AH Single-dose pharmacokinetics of varenicline, a selective nicotinic receptor partial agonist, in healthy smokers and nonsmokers. J Clin Pharmacol. 2006;46(9):991-998.

29. Obach RS, Reed-Hagen AE, Krueger SS, et al. Metabolism and disposition of varenicline, a selective alpha4beta2 acetylcholine receptor partial agonist, in vivo and in vitro. Drug Metab Dispos. 2006;34(1): 121-130.

30. Niaura R, Hays JT, Jorenby DE, et al. The efficacy and safety of varenicline for smoking cessation using a flexible dosing strategy in adult smokers: a randomized controlled trial. Curr Med Res Opin. 2008; 24(7):1931-1941.

31. Nides M, Oncken C, Gonzales D, et al. Smoking cessation with varenicline, a selective alpha4beta 2 nicotinic receptor partial agonist: results from a 7-week, randomized, placebo- and bupropion-controlled trial with 1-year follow-up. Arch Intern Med. 2006;166(15):1561-1568.

32. Oncken C, Gonzales D, Nides M, et al. Efficacy and safety of the novel selective nicotinic acetylcholine receptor partial agonist, varenicline, for smoking cessation. Arch Intern Med. 2006;166(15):1571-1577.

33. Jorenby DE, Hays JT, Rigotti NA, et al. Efficacy of varenicline, an alpha4beta2 nicotinic acetylcholine receptor partial agonist, vs placebo or sustained-release bupropion for smoking cessation: a randomized controlled trial. JAMA. 2006;296(1):56-63.

34. Gonzales D, Rennard SI, Nides M, et al. Varenicline, an alpha4beta2 nicotinic acetylcholine receptor partial agonist, vs sustained-release bupropion and placebo for smoking cessation: a randomized controlled trial. JAMA. 2006;296(1):47-55.

35. Tonstad S, Tonnesen P, Hajek P, Williams KE, Billing CB, Reeves KR Effect of maintenance therapy with varenicline on smoking cessation: a randomized controlled trial. JAMA. 2006;296(1):64-71.

36. Tonstad S, Davies S, Flammer M, Russ C, Hughes J. Psychiatric adverse events in randomized, double-blind, placebo-controlled clinical trials of varenicline: a pooled analysis. Drug Saf. 2010;33(4):289-301.

37. Food and Drug Administration. FDA drug safety communication: safety review update of Chantix (varenicline) and risk of neuropsychiatric adverse events. Available from: http://www.fda.gov/Drugs/DrugSafety/ ucm276737.htm. Accessed August 2015.

38. Meyer TE, Taylor LG, Xie S, et al. Neuropsychiatric events in varenicline and nicotine replacement patch users in the Military Health System. Addiction. 2013;108(1):203-210.

39. Gibbons RD, Mann JJ. Varenicline, smoking cessation, and neuropsychiatric adverse events. Am J Psychiatry. 2013;170(12):1460-1467.

40. Thomas KH, Martin RM, Knipe DW, Higgins JP, Gunnell D. Risk of neuropsychiatric adverse events associated with varenicline: systematic review and meta-analysis. BMJ. 2015;350:h1109.

41. Food and Drug Administration. FDA Drug Safety Communication: Safety review update of Chantix (varenicline) and risk of cardiovascular adverse events. Available from: http://www.fda.gov/Drugs/DrugSafety/ ucm330367.htm. Accessed August 2015.
42. Singh S, Loke YK, Spangler JG, Furberg CD. Risk of serious adverse cardiovascular events associated with varenicline: a systematic review and meta-analysis. CMAJ. 2011;183(12):1359-1366.

43. Hays JT. Varenicline for smoking cessation: is it a heartbreaker? CMAJ. 2011;183(12):1346-1347.

44. Prochaska JJ, Hilton JF. Risk of cardiovascular serious adverse events associated with varenicline use for tobacco cessation: systematic review and meta-analysis. BMJ. 2012;344:e2856.

45. Mills EJ, Thorlund K, Eapen S, Wu P, Prochaska JJ. Cardiovascular events associated with smoking cessation pharmacotherapies: a network meta-analysis. Circulation. 2014;129(1):28-41.

46. Pachas GN, Cather C, Pratt SA, et al. Varenicline for smoking cessation in schizophrenia: safety and effectiveness in a 12-week, open-label trial. J Dual Diagn. 2012;8(2):117-125.

47. Evins AE, Cather C, Pratt SA, et al. Maintenance treatment with varenicline for smoking cessation in patients with schizophrenia and bipolar disorder: a randomized clinical trial. JAMA. 2014;311(2):145-154.

48. Koegelenberg CF, Noor F, Bateman ED, et al. Efficacy of varenicline combined with nicotine replacement therapy vs varenicline alone for smoking cessation: a randomized clinical trial. JAMA. 2014;312(2): $155-161$.

49. Ramon JM, Morchon S, Baena A, Masuet-Aumatell C. Combining varenicline and nicotine patches: a randomized controlled trial study in smoking cessation. BMC Med. 2014;12:172.

50. Ebbert JO, Hatsukami DK, Croghan IT, et al. Combination varenicline and bupropion SR for tobacco-dependence treatment in cigarette smokers: a randomized trial. JAMA. 2014;311(2):155-163.

51. Ebbert JO, Hughes JR, West RJ, et al. Effect of varenicline on smoking cessation through smoking reduction: a randomized clinical trial. JAMA. 2015;313(7):687-694.

52. Catz SL, Jack LM, McClure JB, et al. Adherence to varenicline in the COMPASS smoking cessation intervention trial. Nicotine Tob Res. 2011;13(5):361-368.

53. Suehs BT, Davis C, Galaznik A, Joshi AV, Zou KH, Patel NC. Association of out-of-pocket pharmacy costs with adherence to varenicline. J Manag Care Spec Pharm. 2014;20(6):592-600.

54. Liberman JN, Lichtenfeld MJ, Galaznik A, et al. Adherence to varenicline and associated smoking cessation in a community-based patient setting. J Manag Care Pharm. 2013;19(2):125-131.

55. Hollands GJ, McDermott MS, Lindson-Hawley N, Vogt F, Farley A, Aveyard P. Interventions to increase adherence to medications for tobacco dependence. Cochrane Database Syst Rev. 2015;2:CD009164.

56. Nollen NL, Cox LS, Nazir N, et al. A pilot clinical trial of varenicline for smoking cessation in black smokers. Nicotine Tob Res. 2011 13(9):868-873.
Patient Preference and Adherence

\section{Publish your work in this journal}

Patient Preference and Adherence is an international, peer-reviewed, open access journal that focuses on the growing importance of patient preference and adherence throughout the therapeutic continuum. Patient satisfaction, acceptability, quality of life, compliance, persistence and their role in developing new therapeutic modalities and compounds to optimize

\section{Dovepress}

clinical outcomes for existing disease states are major areas of interest for the journal. This journal has been accepted for indexing on PubMed Central. The manuscript management system is completely online and includes a very quick and fair peer-review system, which is all easy to use. Visit http://www. dovepress.com/testimonials.php to read real quotes from published authors. 